\title{
The anti-inflammatory stage of monocytes after long-term stimulation with LPS is mediated by p38 MAP kinase dependent epigenetic silencing D Viemann ${ }^{* 2}$, P Koenen ${ }^{1}$, K Barczyk ${ }^{1}$, L Steinmueller ${ }^{1}$ and J Roth ${ }^{1}$
}

\author{
Address: ${ }^{1}$ University Hospital of Muenster, Institute of Immunology, Muenster, Germany and ${ }^{2}$ University Hospital of Muenster, Department of \\ Pediatrics, Muenster, Germany \\ * Corresponding author
}

\author{
from 15th Paediatric Rheumatology European Society (PreS) Congress \\ London, UK. 14-17 September 2008 \\ Published: 15 September 2008 \\ Pediatric Rheumatology 2008, 6(SuppI I):PI23 doi:10.II86/I546-0096-6-SI-PI23
}

This abstract is available from: http://www.ped-rheum.com/content/6/SI/PI23

(c) 2008 Viemann et al; licensee BioMed Central Ltd.

Lipopolysaccharide (LPS) as major constituent of Gramnegative bacteria is known to elicit a rapid pro-inflammatory primary response in immune cells. Multiple findings indicate that monocytes next to its crucial function in the early stage of LPS signaling might additionally play an essential role in the resolution of systemic inflammatory responses. We therefore compared gene expression profiles of short-term and long-term LPS-stimulated monocytes. Surprisingly, we revealed an anti-inflammatory gene expression program after long-term LPS treatment. Blocking different signaling pathways revealed p38 MAP kinase to be significantly involved in the regulation of this anti-inflammatory program. Functional clustering analysis showed that chromatin remodeling genes are significantly overrepresented in the group of p38 MAP kinasedependent genes. To test whether epigenetic modifications cause transcriptional silencing in long-term LPStreated monocytes and whether this process is p38 MAP kinase-dependent we performed chromatin-immunoprecipitations. We confirmed for pro-inflammatory genes an increased trimethylation of histone 3 (H3K4me3) and increased acetylation of histone 4 (AcH4) after 4 h LPS treatment indicating increased transcription whereas after $16 \mathrm{~h}$ of LPS treatment AcH4 decreased. Blocking p38 MAP kinase reversed the long-term LPS effect causing a strong increase of AcH4 and methylation of $\mathrm{K} 79$ both indicators of high transcriptional activity. Our results show that p38 MAP kinase contributes significantly to an anti-inflammatory gene expression program in monocytes after long- term LPS treatment. The application of p38 MAP kinase inhibitors currently proposed as novel anti-inflammatory agents might result in deleterious effects on innate immune-regulatory mechanisms. 